\title{
A Pizza: Delícia de Súditos e Reis entre a Oralidade e a Literatura
}

\author{
Fabiano Dalla Bona ${ }^{1}$
}

RESUMO: Ao examinarmos a alimentação, além de suas funções biológicas, ela nos parece pertinente a todos os aspectos da cultura e da civilização. O presente artigo pretende sondar algumas das abordagens da comida nos escritos literários, de modo particular naqueles da literatura napolitana. Propõe ainda uma análise das relações histórico-sociais entre a comida e as obras literárias, além do prazer ligado aos alimentos, em particular a pizza. PALAVRAS-CHAVE: literatura italiana; literatura napolitana; culinária; gastronomia; identidade; tradição oral.

ABSTRACT: Quando si esamina il tema dell'alimentazione, oltre alle funzioni biologiche essa ci fa pensare a tutti gli aspetti della cultura e della civiltà. Quest'articolo propone un approccio sul ruolo del cibo negli scritti letterari, in particolare in quelli della letteratura napoletana. Propone, inoltre, un'analisi delle relazioni storico-sociali tra cibo e opere letterarie, oltre 
al piacere che il cibo provoca, in particolare la pizza.

PAROLE CHIAVE: letteratura italiana; letteratura napoletana; culinaria; gastronomia; identità; tradizione orale.

ABSTRACT: When we examine the theme of food - apart from its biological functions - , it allows us to discuss many aspects of culture and civilization. This work aims at discussing the presence and importance of food in literature, more specifically in Neapolitan literature. It also aims at analyzing historical and social relations between food and literary works, specially for pizza.

KEYWORDS: italian literature; neapolitan literature; cookery: gastronomy; identity; oral tradition. 


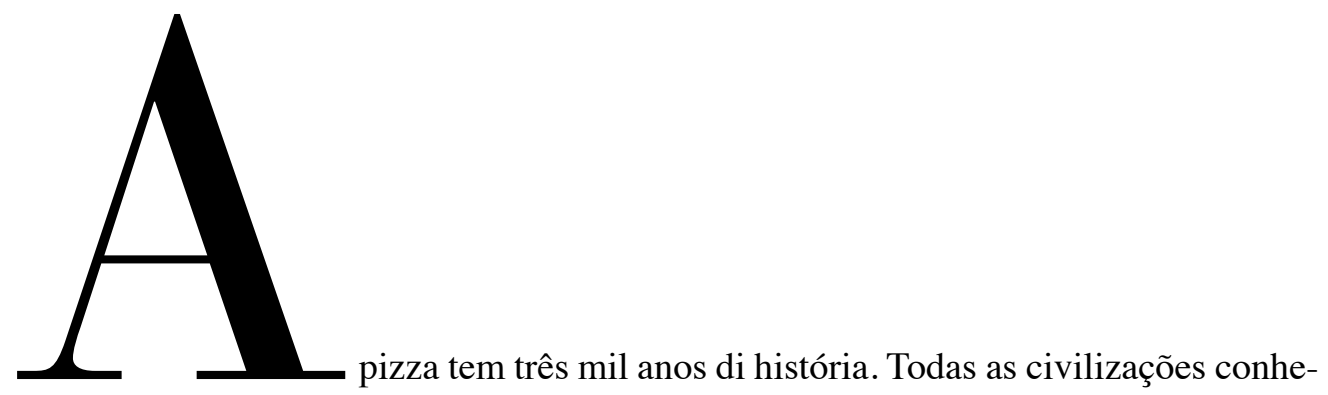
ceram formas diferentes de pães e similares, produzidas com farinha e água, assadas sobre pedras incandescentes ou em primitivos fornos, fonte de nutrição fundamental na alimentação humana. As tortillas mexicanas e as massas de arroz dos países do Oriente resgatam o mesmo gesto original, a circularidade transmitida pela mão de quem amassa, comprime e alisa. Trata-se de uma comida em forma circular (de sol ou de lua), em consonância com a invenção da roda. Pensemos na pita grega e árabe, o nan indiano e o blini eslavo: todos de formato circular, misto de prato e alimento.

Se examinarmos a origem histórica da pizza verificaremos que, do Egito à antiga Roma, foi criada uma série de iguarias que recordam, quer na sua composição quer em seu cozimento, a atual pizza. No Antigo Egito, era costume celebrar o genetlíaco do faraó consumindo um pão achatado e temperado com ervas aromáticas. Como atesta Plínio o Velho, sem esse invento egípcio não teríamos, provavelmente, conhecido o verdadeiro pão (MINICHINI, 2002, p. 41). 
Na Grécia, Archiloco (680-645 a.C.), o poeta-soldado, em alguns de seus versos nos informa de possuir em seu bornal, "focaccia impastata, l'alimento principale del soldato" (ALONI, 1981, p. 49).

Numerosos são os testemunhos de escritores gregos a propósito de diversos tipos de "pizza", como a maza, sem fermentação e, mais tarde, no mundo latino, nas suas versões fermentadas como a placenta e a offa, preparadas com água e cevada, o cereal básico na alimentação dos latinos. Segundo uma versão clássica, uma simples massa feita de farinha, água, fermento e sal, nasceu como uma fogaça (focaccia) nas cozinhas romanas, servindo de prato para receber as iguarias durante as refeições. De acordo com essas informações, teria sido criada pelo romano Marco Gavio Apicio, reconhecido por seu livro de receitas De Re Coquinaria (APICIO, 1990).

Uma das primeiras descrições literárias da pizza se encontra na obra L'economia del cittadino in Villa, do marquês, caçador e soldado bolonhês Vincenzo Tanara. Publicada pela primeira vez em 1644, subdividida em vários livros, é um texto de grande importância, pois, pela primeira vez, se escreve sobre agricultura com uma olhar crítico, voltado para as exigências do mercado e para a obtenção de lucros. O livro apresenta uma série de receitas, ditadas pelas preferências do autor, com comentários e notas históricas. Traz, também, uma lista de fontes bibliográficas dos clássicos da literatura grega e latina que discorrem sobre a pizza, conforme podemos atestar nas palavras do autor:

Dietro a questo dovria seguire il racconto d'innumerabili pizze Romane, Chiacciate, Tosche, placente Latine, e Crescente Bolognese, ma perche ogn'uno se ne può comporre a suo modo, bastarà il sapersi, che ogni cosa, che si mistifica con questoo pane, gli apporta gusto. Prima il sale solo, poi ogn'unto come grasso, butiro, \& oglio, indi mandorle, over noci rotte, similmente a quelle pizze si può mistificar ogni frutto, ogni carne, \& ogn'herba, e da questo ne venne da prima l'inventione di far i pastizzi ampliati poi da un Sabino Galla, Cuoco di Clodoveo Rè di Francia. (TANARA, 1674, p. 38).

O estudo da etimologia desse termo traz histórias pitorescas, pois muitas das explicações da nomenclatura recordam o primitivismo da pizza. O seu nome teria se 
originado do grego pláx, que significa superfície plana, sendo que, no mundo romano, os vendedores desse tipo de massa chamavam-se placentarii. Outra vertente informa que o nome pizza viria de pinsa, substantivo do verbo latino pinsere e do frequentativo análogo pistare, sendo os seus produtores os padeiros, que eram chamados de pistores; existia ainda o termo pistus, que designava a massa mole comum a pães e fogaças; este mesmo termo era usado para se referir ao ato de moer, reduzir a pó (LA CECLA, 1998, p. 43).

A consulta ao Vocabulário Etimológico de Pianigiani revela que o termo pizza deriva do gótico-lombardo, antigo alemão, bizzo ou pizzo, traduzido como pedaço de pão, focaccia (PIANIGIANI, 1926). Já Puoti, define pizza como "pane schiacciato messo a cuocere al forno, focaccia, schiacciata, schiacciata unta, stiacciata" (PUOTI, 1850, p. 348).

Segundo a definição de Francesco De Bourcard, "la pizza non si trova nel vocabolario della Crusca perché si fà col fiore, e perché è una specialità dei napoletani, anzi della città di Napoli". Na obra, Usi e costumi di Napoli e contorni descritti e dipinti, temos descrições importantes da província de Nápoles. Durante vinte anos De Bourcard - napolitano neto de suíços - traçou as características geográfico-antropológicas de Nápoles, no período compreendido entre 1847 e 1866 . Trata-se de uma obra de grande importância para este estudo, não só pela cuidadosa descrição dos hábitos da época, dos personagens populares, festas, cerimônias e cultos, mas também pelos cem desenhos aquarelados que ilustram os dois volumes da obra. Observemos o relato da gênese da pizza:

Prendete um pezzo di pasta, allargatelo o distendendolo col matterello o percuotendo colle palme delle mani, metteteci sopra quel che vi viene in testa, conditelo di olio o di strutto, cuocetelo al forno, mangiatelo, e saprete che cosa è una pizza. Le focacce e le schiacciate sono alcunché di simile, ma sono l'embrione dell'arte. (DE BOUCARD, 1858, p.123).

O ápice dessa breve história biografada da pizza é na Idade Moderna, após a descoberta do Novo Mundo; sobretudo com o desembarque na Europa do seu principal 
ingrediente, sem o qual é impossível imaginá-la: o tomate. Entretanto, o pomodoro sofreu, inicialmente, uma série de restrições do seu uso na cozinha, pois o Solanun lycopersium era, até então, apenas uma planta exótica cultivada em estufas palacianas. Todavia, a questão da pizza, primeiro como invenção napolitana e depois italiana, é um dado menos importante nessa trajetória histórica, conforme atesta o estudioso La Cecla: "Certamente a Napoli la focaccia dei contadini di Virgilio o la picia di Orazio e la stessa piza attestata nel latino medievale di Gaeta nel 997 diventa un cibo urbano, popolare" (LA CECLA, 1998, p. 46).

No século XVII, a pizza era preparada em fornos à lenha para ser vendida nas ruas e becos da cidade; a comercialização da pizza era feita por um garzone di bottega, um meninote, que carregava um cesto cheio delas em perfeito equilíbrio sobre sua cabeça, já preparadas com diversos ingredientes e levando-as aos clientes com particulares pregões e rimas (CARAVAGLIOS, 1931, p. 23).

Na virada do século XVII para o XVIII, afirmou-se o hábito de degustar as pizzas nos locais onde eram fabricadas; assim os fornos representam as primeiras pizzarias, evidenciando o crescente gosto pelo alimento na vida alimentar do populacho napolitano.

Esse hábito napolitano nos é descrito por Peter Nicholson Gunn, escritor australiano, que informa, ainda, tratar-se de uma comida exclusivamente popular naquela época, mas com admiradores também entre os nobres:

Nel 1618 il ministro Salines stava intrattenendo il Duca [d'Ossuna, Don Pietro Giron, Vice-rei de Napoli] e le sue donne con una rappresentazione in casa sua, allorché Dorotea di Capua, Marchesa di Campolattaro, a quel tempo amante di Sua Eccellenza, fu presa dall'improvviso desiderio di mangiare che viene alle donne enceinte, e interruppe gli attori ad alta voce chiedendo: "Pizze, pizze all'olio". Quando le pizze arrivarono molte altre dame si unirono a lei nello spuntino. (GUNN, 1971, p. 118-119).

Nos primeiros anos do século XVIII, as pizzarias eram, em seu aspecto, muito mais fornos do que estabelecimentos de restauração. Somente na segunda metade da- 
quele século, das oitenta pizzarias existentes em Nápoles, umas vinte delas colocaram a disposição do público uma área com mesas para o consumo, in loco, da pizza. Dessa forma, perde aquela conotação de "comida de rua", adquirida dos ambulantes, como também testemunhou Alexandre Dumas, em 1835, em visita a Nápoles:

La pizza est une espèce de talmouse comme on en fait à Saint-Dennis; elle est de forme ronde et se pétrit de la même patê que le pain. Elle est de différentes largeurs, selon le prix. Une pizza de deux liards suffit à un homme; une pizza de deux sous doit ressasier toute la familie. Au premier abord, la pizza samble un mets simple; après examen, c'est un mets composé. La pizza est à l'huile, la pizza est au lard, la pizza est au saindoux, la pizza est au fromage, la pizza est aux tomates, la pizza est aux petits poissons; c'est le thermomètre gastronomique du marché: elle hausse ou baisse de prix, selon le cours des ingrédiens sus-désignés, selon l'abondance ou la disette de l'année. Quand la pizza aux poissons est à un démi-grain, c'est que la pêche a été bonne; quand la pizza à l'huile est à un grain, c'est que la récolte a été mauvaise. (DUMAS, 1851, p. 91)

Segundo La Cecla, em 1727 existia a pizzaria Zi' Ciccio, na Piazza Cavour; em 1732, aparece a pizzaria de 'Ntuono Testa na Salita Santa Teresa, local onde o rei Ferdinando I costumava ir incógnito. Em 1738, outra pizzaria homônima a esta nasce em Port'Alba, e ainda em funcionamento nos dia hoje; em 1748, abre-se outra em Spaccanapoli; em 1750, abre-se na Porta San Gennaro, a pizzaria Capasso e, finalmente, em 1760, a pizzaria Da Pietro, que mais tarde passou a ser denominada Brandi (LA CECLA, 1998, p. 46).

Naturalmente, a pizza foi afirmando-se como prato cotidiano, almoço e jantar do povo. Na obra de Matilde Serao, Il ventre di Napoli, há também essa referência à preferência dos napolitanos pela pizza, conforme podemos observar no trecho que segue, quando informa que "la pizza rientra nella larga categoria dei commestibili che costano un soldo, e di cui è formata la colazione o il pranzo, di moltissima parte del popolo napoletano" (SERAO, 2002, p. 53).

Ao longo de todo o século XIX, temos as descrições dos notórios pizzaiolos que, ambulantes ou não, continuam a fornecer aos napolitanos as mais diversas qualidades 
de pizza, para todos os tipos de bolsos; dessa forma, a iguaria entra definitivamente como tema do folclore napolitano, tornando-se um ícone. Em Il paese di Cuccagna, Matilde Serao nos revela a preferência partenopeia pela pizza, principalmente no período de carnaval:

I celebri tre pizzaiuoli, del Vico Freddo e Chiaia, del largo Carità, di Port'Alba, avvertivano il pubblico amatore delle pizze, di quella doppia pizza che si chiama calzone e di quella frittata che ha il nome di filoscio, nonché delle costolette alla pizzaiuola, che essi sarebbero stati aperti sino alla mattina, con vino di Marano e del Monte di Procida. (SERAO, 1920, p. 102).

A narrativa de Serao traz uma contribuição sobre esse tema ao evidenciar a sua preocupação não somente com a história de Nápoles e com as suas tradições, mas também a sua tomada de posição como uma ativista em favor da resolução dos problemas de sua cidade. Em outra obra de sua autoria, Il ventre di Napoli, denunciou o desinteresse do governo local pelos problemas da cidade, solicitando uma sensibilização da nação no sentido de dar uma solução para tais questões. Na obra, ela sublinha as profundas contradições da sua terra, fundidas num tom de enquete sociológica e de pesquisa jornalística, aliadas a uma escritura eficaz e expressiva, capaz de exprimir a denúncia e a dor dos mais pobres. Ela intui uma correspondência entre a cidade urbanística e cidade humanística, entre interno e externo, entre paisagem física e paisagem moral, utilizando termos lexicais emblemáticos como sventramento e risanamento, que são conduzidos à dimensão metafórica do corpo na sua degeneração; termos que, utilizados pelos urbanistas, conduzem à concepção de corpo urbano doente, socialmente falando.

Il pizzaiuolo che ha bottega, nella notte, fa un gran numero di queste schiacciate rotonde, di una pasta densa, che si brucia, ma non si cuoce, cariche di pomidoro quasi crudo, di aglio, di pepe, di origano; queste pizze in tanti settori da un soldo, sono affidate a un garzone, che le va a vendere in qualche angolo di strada, sovra un banchetto ambulante e lì resta quasi tutto il giorno, con questi settori di pizza che si gelano al freddo, che si ingialliscono al sole, mangiati dalle mosche. Vi sono an-

5. "Cenava sempre con parsimonia e alla fine del pasto si arrotolava una sigaretta con tabacco di cattiva qualità." Fernando Pessoa presenta Bernardo Soares (PESSOA, 2003). 
che delle fette da due centesimi, pei bimbi che vanno a scuola; quando la provvigione è finita, il pizzaiuolo la rifornisce, sino a notte. Vi sono anche, per la notte, dei garzoni che portano sulla testa un grande scudo convesso di stagno, entro cui stanno queste fette di pizza e girano pei vicoli e danno un grido speciale, dicendo che la pizza ce l'hanno col pomidoro e con l'aglio, con la muzzarella e con le alici salate. Le povere donne sedute sullo scalino del basso ne comprano e cenano, cioè, pranzano, con questo soldo di pizza. (SERAO, 1920, p. 54).

A preferência desse alimento entre nobres nasce com os reis de Bourbon chegando até os Savóia, que demonstraram o seu apreço pela iguaria napolitana, acabando por deixar traços marcantes na sua história. O fato mais marcante aconteceu em 1889, de acordo com os relatos históricos, quando a Rainha Margherita, desejosa de romper a "monotonia da cozinha francesa", quis experimentar a pizza; assim, mandou um mensageiro da Real Casa convidar à corte o pizzaiolo Raffaelle Esposito, titular da pizzaria Pietro... e basta così. O pizzaiolo e sua mulher foram até o Palácio de Capodimonte, levando, a bordo de uma charrete, os ingredientes necessários ao preparo da pizza. No palácio existia já um forno de pizza, ao lado dos fornos para a queima da real porcelana construídos pelos Habsburgos, ou melhor, pelo filho de 'Ntuono, por ordem de Ferdinando II. O pizzaiolo Esposito usa o forno existente e prepara três pizzas. Buscando evitar o uso do alho da pizza alla marinara, que era pouco recomendável à feminilidade real, decidiu-se, então por um tipo de pizza bianca, feita com azeite, queijo e manjericão, e por outra, com os cecenielle, peixinhos diminutos, e uma terceira guarnecida com tomate, mussarela e manjericão, vermelha, branca e verde. Todos os relatos do fato são idênticos, até o preparo das três pizzas no palácio. A diferença começa, exatamente, no propósito dessas pizzas; em alguns documentos afirma-se que a pizza com as cores da bandeira italiana, tendo por base os motivos patrióticos, teria sido feita de improviso e denominada com o nome da rainha. Outra versão afirma que a pizza com tomate, mussarela e manjericão já existia e que tal evento serviu apenas para dar-lhe um nome, um sentido e uma função histórica (LA CECLA, 1998, p. 49).

Eis o texto do documento citado, preservado na sede da pizzaria em Nápoles: 
L'Antica Pizzeria Brandi conserva ancora oggi un documento a firma "devotissimo Galli Camillo, capo dei servizi di tavola della real casa” del giugno 1889, nel quale si ringrazia S. G. Raffaele Esposito, dell'allora pizzeria "Pietro e Basta Così", per le qualità di pizza, tra cui la celeberrima pomodoro e mozzarella, confezionate per Sua Maestà la Regina Margherita, che, come sottolinea il testo, vennero trovate buonissime. $^{2}$

A pizza Marguerita é um exemplo clássico de como a lenda do surgimento de um alimento se confunde com os dados históricos. A história, verdadeira ou falsa que seja, é um caso extraordinário de invenção da tradição, pois contém todos os elementos de redefinição de um ponto de vista. Nela encontramos o populismo típico da recém-nascida monarquia da Itália unificada, capaz de apropriar-se de símbolos e mitos precedentes e levá-los para o Norte. Os Savóia, vindo de muitos quilômetros de distância, substituindo os antecessores Bourbon, imitam o mesmo ritual da refeição da pizza.

Essa passagem ilustra o percurso desse alimento de Nápoles para a Itália e da Itália para o mundo. Voltemos ao texto literário, mais precisamente à Matilde Serao, que nos conta uma dessas aventuras, aliás, pouco afortunada, na opinião da escritora, quando da instalação de uma pizzaria em Roma:

Un giorno, un industriale napoletano ebbe un'idea. Sapendo che la pizza è una delle adorazioni cucinarie napoletane, sapendo che la colonia napoletana in Roma è larguissima, pensò di aprire una pizzeria in Roma. Il rame delle casseruole e dei ruoti vi luccicava, il forno vi ardeva sempre; tutte le pizze vi si trovavano; pizza al pomidoro, pizza con mozzarella e formaggio, pizza con alici e olio, pizza con olio, origano e aglio. Sulle prime la folla vi accorse; poi andò scemando. La pizza, tolta al suo ambiente napoletano, pareva una stonatura e rappresentava una indigestione; il suo astro impallidì e tramontò, in Roma; pianta esotica, morì in questa solennità romana. (SERAO, 1920, p. 53)

Podemos perceber que Serao descreve o ocaso da pizza fora do seu ambiente de nascimento no século XIX. Entretanto, o que se verificou no século seguinte foi exatamente o contrário, pois a pizza se difundiu em escala nacional e mundial, conquistando

2. Disponível em: < www.brandi.it > Acesso em 15/01/2009. 
consumidores em toda a Europa, nas Américas e no Oriente, tornando-se, sem exagero, patrimônio de toda a humanidade.

Outro escritor napolitano, que irá imortalizar a pizza, é Giuseppe Marotta, autor de San Gennaro non dice mai no. A obra é uma descrição do seu retorno a Nápoles, em 1947, após o término da Segunda Guerra Mundial. Nápoles foi destruída física e moralmente pelas tropas alemãs, mas o espírito alegre, bonachão e apreciador da boa mesa não fora cancelado pela crueldade estrangeira. Marotta, num diálogo com o autor de canções napolitanas Giuseppe Rossetti, outro apaixonado pela cidade e por suas tradições, ouve um decantar das qualidades da pizza e escolhe como cenário a tradicional pizzaria do Largo della Carità:

Ocupammo un lindo tavolaro della illustre "pizeria” al Largo della carità, e Giuseppe Rossetti parlò. Ah la "pizza”. Ł̇ dolce, è amara, è lunga, è breve, è antica, è nuova, è sicura, è imprevedibile, è pane, è companatico, è superlativamente buona: è la "pizza". Mi piace questo cibo di poveri, commovente e pieno di simboli come l'ostia. Alla "pizza" potete confidare, mentre la mangiate, qualsiasi cosa; quanto dovete d'affitto o perché avete perduto l'impiego, chi avete attirato in un vostro piccolo imbroglio o in che imbroglio siete caduto; tutto potete dirlo, tutto. Nessun alimento vi fa compagnia come la "pizza"; è una luna nel piatto, per profonda che sia la notte del vostro appetito potrete sempre, su una "pizza", orientarvi e riprendere il cammino. Di farina, di acqua, di strutto, di pomodoro, di mozzarella e di calore si compone la "piz$z a$ ”: badate non solo il calore del forno che la stria di lievi bruciature, bensì il calore umano delle dita di chi la prepara. Il "pizzaiuolo" dietro il banco, con che arte e con che amore appiattisce e stende il cubo di pasta: sono piccoli colpi, ora largui e molli, ora aguzzi e penetranti, delle mani piccole e intelligenti come quelle degli ostetrici; poi la candida piattaforma è pronta a ricevere il condimento: il "pizzaiuolo" la picchietta di strutto, vi sparge i triangoletti di mozzarella e un pizzico di formaggio, vi spruzza la salsa e dice: "Andiamo con la palla; pronti, andiamo". Qualche minuto trascorre, infine la "pizza" è nata, trasalisce ancora come nel forno mentre me la depongono davanti sul marmo del tavolino; “a noi due, ora”. (MAROTTA, 1977, p. 56-57).

As histórias de Nápoles e da pizza podem sugerir, ainda, uma série de outras his- 
tórias, sobretudo, porque a cidade se tornou um lugar do imaginário, cidade contada através de estereótipos construídos, segundo a ideologia dos visitantes que se viam fascinados por aquela realidade complexa e estimulante. A própria cidade fez questão de reproduzir os seus estereótipos, acentuando, na própria apresentação, os aspectos que os "outros" queriam ver, através de um jogo de imagens e de apelos a ela correlatos. Através desse conjunto de elementos, denominado napoletaneità, foi elaborada e veiculada a imagem segundo a qual o povo napolitano, não obstante a miséria, consegue manter aquelas características próprias de sua natureza, atenuando, assim, o contraste entre subdesenvolvimento sócioeconômico e a solaridade mediterrânea (SIGNORELLI, 2002, p. 15).

Esse fato pode ser exemplificado através de uma lenda da pizza, muito conhecida em Nápoles, sobre esse aspecto do povo que, para viver, faz uso de pequenos expedientes, utilizando-se de verdadeiras negociatas, como é o caso do personagem protagonista da história de Totó Sapore.

Conta-se que, na primeira metade do século XVIII, o cozinheiro da corte dos Bourbon, na capital do Reino de Nápoles e das Duas Sicílias, era um tal Totó Sapore, verdadeiro artista do fogão e muito mimado pelo rei. Um dia, um invejoso colocou um fio de cabelo no magnífico assado que ele havia preparado para o jantar real. Embora inocente, o cozinheiro acabou na prisão. No cativeiro, o artista inconformado, arquitetou um plano para ser libertado; escreveu um bilhete ao soberano pedindo a liberdade em troca de uma nova iguaria. Tal iguaria possuía as seguintes características: "Deve ser cozida em menor tempo que o macarrão, não será nem primeiro e nem segundo prato, nem carne e nem peixe; será quente como o inferno e deliciosa como o paraíso; redonda como o mundo e cheia de fogo como o sol de verão. Majestade", assim escrevia Totó Sapore em sua carta, "ao criar tal prato, sem dúvida, serei merecedor da liberdade".

O soberano, instigado na sua gula, aceitou a proposta e, logo após a saída de Totó da prisão, chegava à sua mesa o novo prato. Quando o rei experimentou a massa macia e crocante ao mesmo tempo, dourada e perfumada pelo vermelho do tomate, o engenhoso cozinheiro foi libertado com a condição de preparar a delícia todos os dias para a inteira família real (PIUMINI, 2003). 
Conforme vimos anteriormente, o consumo da pizza se deu, inicialmente, em outros espaços, diferentes desse contado na lenda. Isso porque, na realidade, a pizza era comida nas feiras e mercados, nas ruas e praças de Nápoles, da mesma forma que os macarrões. A diferença entre a pizza e o macarrão, ambas comidas de rua, reside no fato de que a primeira é uma comida seca e a segunda é uma comida úmida. Tal diferença determinou o destino maior da pizza, que é o de ser algo para ser comido "fora", inclusive sem prato, com as mãos, dobrando-as em quatro partes, a libretto como se diz em Nápoles. A pizza é algo público, como sugerem Sabban e Serventi; trata-se de uma comida seca que acompanha a agilidade da vida na praça. O caráter do seu consumo é prosaico, enquanto o úmido do macarrão requer o recurso de um local "seguro" para ser comido (SABBAN \& SERVENTI, 2004, p. 158).

A lenda da pizza é um exemplo que ilustra como a oralidade é retomada pela literatura através de intelectuais que ocuparam lugar de destaque na história literária napolitana, como Matilde Serao. À escritora foi atribuída uma específica representatividade regional, que assumiu tonalidades pedagógicas e se tornou uma "voz" da cidade (RANISIO, 2003, p. 7).

A narração oral nos conduz aos domínios do fantástico, do irreal, do maravilhoso. De fato, trata-se de contos nos quais se mantém o estado de incerteza entre o real e o mistério, dados pela ilusão ou pela imaginação, induzindo a um estado de hesitação que é determinado não somente pelo acontecimento estranho, mas também pelo modo no qual nos é contado (TODOROV, 1975).

Hoje, certos contos nos parecem construções culturais ligadas a um determinado período histórico, como no caso de Totó Sapore. Por outro lado, como sustenta VelayVallantin, a literatura oral não é uma emanação espontânea do povo, segundo uma conhecida formulação romântica; ao contrário, está fortemente ancorada a um contexto específico, não existindo, ou não se difundindo a não ser dentro de um sistema mais ou menos complexo, cujo modelo geral é uma reunião de dados na qual o narrador é quem toma a palavra (VELLAY-VALLANTIN, 1992, p. 23).

Não muito diferente é a opinião do folclorista e antropólogo calabrês Lombardi Satriani: 
Pur nell'universalità narrativa della fiaba tali specificità riflettono situazioni economico-sociali, sono il frutto di determinati processi storici. Allora il problema diventa quello dell'equilibrio fra l'universalità della fiaba e la sua storicità, quale prodotto culturale frutto di una plasmazione culturale specifica. (SATRIANI, 1992, p. 338).

Assim sendo, Nápoles é uma cidade que conta e, ao mesmo tempo, se conta e se representa através de seus cidadãos, afirmando e difundindo a sua própria imagem cultural. Tendo sido sempre uma das metas preferidas do Grand Tour do período romântico, visitantes ilustres, de Goethe a Dumas, descreveram as impressões que a sociedade napolitana lhes suscitara, contribuindo para a construção e para a elaboração do mito de Nápoles, logo amplamente difundido por toda a Europa por meio de suas obras. A tais elaborações corresponde, em nível visual, a iconografia da cidade ligada ao paisagismo dos séculos XVIII e XIX e, mais tarde, à fotografia. Nápoles é uma das cidades mais fotografadas do mundo e, por isso, é chamada de "cidade cartão postal". As imagens que constituem os principais topoi da cidade são o Vesúvio, os bandolins, a pasta e, naturalmente, a pizza.

\section{Referências bibliográficas}

ALONI, A. Le muse di Archiloco: ricerche sullo stile archilocheo. Copenhagen: Museum Tusculanum Press, 1981.

APICIO. La cucina dell'antica Roma. Trad. C. Vasco. Roma: Newton \& Compton, 1990.

BORDO, V. \& SURRUSCA, A. (org.) L'Italia del pane: guida alla scoperta e alla conoscenza. Bra: Slow Food Editore, 2003.

CARAVAGLIOS, C. Voci e gridi dei venditori in Napoli. Catania: Libreria Tirelli, 1931.

DE BOURCARD, F. Usi e costumi di Napoli e contorni descritti e dipinti. Napoli: Tipografia G. Nobile, 1858 , v.II.

DUMAS, A. Impressions de voyage: Le Corricolo. Paris: Michel Lévy Fréres, 1851.

GUNN, P. Napoli un palinsesto. Napoli: Marotta Editori, 1971.

LA CECLA, F. La pasta e la pizza. Bologna: Il Mulino, 1998.

MAROTTA, G. San Gennaro non dice mai no. Milano: Bompiani, 1977.

MINICHINI, V. L'eternità del pane: piccola storia dell'alimento più antico. Napoli: Tulio 
Pironti Editore, 2002.

PIANIGIANI, O. Vocabolario etimologico. Firenze: Ariani, 1926. Disponível em: < www. etimo.it > Acesso em 14/01/2009.

PIUMINI, R. Il cuoco prigioniero. Roma: Nuove Edizioni Romane, 2003.

PUOTI, B. Vocabolario domestico napoletano e toscano compilato nello studio. Napoli: Stamperia del Vaglio, 1850.

RANISIO, G. La città e il suo racconto. Roma: Meltemi, 2003.

SATRIANI, L. M. L. Pulcinella: il mito e la storia. Milano: Leonardo, 1992.

SERAO, M. Il paese di Cuccagna. Milano: Treves, 1920. . Il ventre di Napoli. Cava de' Tirreni: Avagliano, 2002.

SIGNORELLI, A. La cultura popolare napoletana, um secolo di vita di uno stereotipo e del suo referente. In: SIGNORELLI, Amalia (org.). Cultura popolare a Napoli e in Campania nel Novecento. Napoli: Edizioni del Millennio, 2002.

TANARA, V. L'economia del cittadino in villa. Venezia: S. Curti, 1674.

TODOROV, T. Introdução à literatura fantástica. São Paulo: Perspectiva, 1975.

VELAY-VALLANTIN, C. L'histoire des contes. Paris: Librairie Fayard, 1992, p. 23. 